I Universidade Estadual de Campinas (Unicamp), Departamento de Sociologia,

Campinas, SP, Brasil

mnicolau@unicamp.br.

https://orcid.org/0000-0003-0893-97 IX

Michel Nicolau Netto'

\title{
AS FRONTEIRAS DO UNIVERSO DO LUXO
}

O Universo do luxo. (2019). Renato Ortiz.

São Paulo: Editora Alameda.

A sociologia é marcada por metáforas geográficas para caracterizar objetos de análise. Esfera (Max Weber), campo (Pierre Bourdieu), mundo (Howard S. Becker) etc. são artifícios que os ana- fronteiras nas quais se inserem seus objetos. Tais metáforas operam em outra fronteira, aquela na qual a sociologia fundou originalmente seu objeto e suas categorias: a sociedade nacional. Não à toa, para uma bibliografia que começa a assumir a globalização como um fenômeno real - não meramente uma ideologia - o surgimento de uma nova totalidade sacrifica justamente as fronteiras. Nessa bibliografia não se demarcam fronteiras, com metáforas geográficas, mas se afirma uma totalidade, um interno sem externo. Novas metáforas nesse sentido se acumulam: aldeia global (Marshall McLuhan), sistema- mundo (Immanuel Wallerstein), sociedade global (Roland Robertson, Octavio Ianni), ecúmeno global (Ulf Hannerz). É o mundo - não no sentido de Becker, mas no sentido do próprio planeta que seria a unidade de análise da sociologia. Como diz Octavio Ianni (2006: I3), descobrimos que "a terra se tornou mundo, [...] que o globo não é mais apenas uma figura astronômica, e sim o território no qual todos encontram-se relacionados e atrelados, diferenciados e antagônicos - essa descoberta surpreende, encanta, atemoriza".

Um mundo no qual importa menos pensar as fronteiras e mais a totalidade. Um mundo no qual as metáforas geográficas estariam condenadas. Não 
é esse, contudo, o mundo que Ortiz percebe em seu mais novo livro, no qual o leitor encontra as fronteiras organizadas em uma metáfora geográfica que lhe dá título: em um universo.

A correlação entre globalização e fronteiras está anunciada desde o início dos trabalhos de Ortiz sobre globalização. Desconfiado com a pressa de alguns autores em negar o espaço, o musical Ortiz - que lançou um álbum de músicas na mesma semana em que lançou seu novo livro - seguiu Paulinho da Viola e levou o barco devagar. No livro Um outro território, publicado em I996 em espanhol, ele se dedicou pela primeira vez a tratar especificamente do espaço. Sua pergunta era a seguinte:

De maneira implícita ou explícita, as análises em Ciências Sociais possuem um certo entendimento do que é o espaço (no caso da Sociologia e da Ciência Política, o território nacional é preponderante). Seria possível mantê-lo no quadro atual das sociedades contemporâneas? Dificilmente (Ortiz, I999: 47).

"Dificilmente", contudo, não o levava a negar o espaço, como se a categoria não fizesse mais sentido na sociedade. Para Ortiz era estranho afirmar que “'o espaço esvaziou', [que] 'o mundo já não possui fronteiras’ [...] [, que a] noção de espaço estaria, pois, no seu ocaso" (Ortiz, I999: 48). Apoiando-se em Durkheim e Mauss (2004), Ortiz afirmava que o espaço não é uma categoria abstrata, mas uma forma de classificação. Como tal, as pessoas o produzem, enquanto representação, para vincular suas vidas, suas relações, e, nesse sentido, o espaço se modifica, mas não desaparece. Isso significou para Ortiz (I999: 50) que "se é verdade que as mudanças recentes da sociedade consolidam um padrão civilizatório particular, o da modernidade-mundo, resta-nos perguntar sobre o tipo de espacialidade que lhe é peculiar". Dessa noção, adianta- se uma agenda de pesquisa: "como se caracteriza, no mundo contemporâneo, uma territorialidade desenraizada? Como compreendê-la, quando ela se amplia para além das fronteiras físicas, envolvendo os indivíduos, as nações e as culturas?" (Ortiz, I 999: 50). O livro O universo do luxo é onde Ortiz (20I9) realiza de maneira mais bem acabada essa agenda. Nele se concretiza justamente a demonstração da produção de um espaço - com fronteiras, trajetos, objetos e pessoas - na globalização.

Antes de desenvolver esse argumento, olhemos como o livro se estrutura e já notemos como a dimensão espacial é transversal. Temos quatro capítulos centrais e as considerações finais (o livro ainda conta com uma introdução e uma digressão final). No primeiro capítulo, "o mercado de bens de luxo", Ortiz apresenta sua dimensão econômica, com dados sobre o consumo de luxo e sua distribuição espacial. Se ali o luxo é tratado em uma dimensão de expansão, no segundo capítulo, "um universo singular”, vemos sua restrição. Nele Ortiz mostra o conceito de universo e o argumento de que o luxo não se "democratiza" (como afirmam alguns autores), mas se globaliza e, nesse processo, produz novas fronteiras, manten- 
do-se inacessível à maior parte das pessoas. No terceiro capítulo, "distinção e sobreposição das fronteiras: arte e luxo", o autor aborda as relações entre arte e luxo, com o surgimento de fundações de marcas de luxo que financiam a arte ou, no caminho inverso, a presença de coleções de luxo em museus de arte. Arte e luxo se aproximam, demonstra Ortiz, mas não se confundem. Se compartilham noções como autoria, unicidade e raridade, distanciam-se em noções como artesanato, central para o luxo e oposto à arte. Tudo funciona como se houvesse uma zona de compartilhamento entre esses dois espaços, mas também fronteiras que não lhes permitem confundir-se. No quarto capítulo, "o mundo dos ricos", Ortiz apresenta o lugar em que o luxo se materializa. Nesse que é o capítulo mais etnográfico do livro o que importa não são os dados (embora eles ajudem nos argumentos), mas os singulares estilos de vida dos ricos. O livro ainda possui um capítulo de "considerações finais" (com o subtítulo "autenticidade e gosto”) que é menos uma conclusão (há ainda uma digressão final), mas o desenvolvimento de uma ideia-chave: se o gosto dos ricos se opera dentro de fronteiras, ele é gosto global em dois sentidos: em sua expansão pelo planeta e em sua condição de definir um novo gosto legítimo, agora global, que atravessa as diversas classes sociais e vários lugares. É rico aqui o diálogo de Ortiz com seu velho interlocutor, Pierre Bourdieu.

Une os capítulos o pressuposto uma das diferenças radicais entre o livro de Ortiz e outros trabalhos que tratam do luxo - de que não importa estabelecer "o que é um objeto de luxo", "o relevante é estabelecer o vínculo existente entre objetos, práticas e instituições" (Ortiz, 2019: 65). Um objeto só é de luxo se ele está em uma rede de relações com outros objetos, práticas e instituições que, em conjunto, produzem o sentido do luxo. Em outras palavras, quem compra um perfume caro pode ser apenas um endinheirado se não souber quais os outros produtos e práticas que correspondem a esse perfume: como viajar, para onde viajar, que água e que vinho beber, que carro dirigir etc. Sem esse código, que ordena suas práticas e seu consumo, o dinheiro lhe permite a compra, mas não o pertencimento ao "universo do luxo". Lidar com isso é o que mais importa às empresas do luxo, e seu trabalho não é fácil: elas precisam dos ricos (é em seu mundo que o luxo se encarna), mas não podem deixar que apenas o dinheiro defina o luxo, pois assim um equivalente universal poderia desmanchar as fronteiras desse universo. Se quem habita o universo do luxo habita o mundo dos ricos, nem todos que habitam o mundo dos ricos podem habitar o universo do luxo. O trabalho dos artífices (que Ortiz define como intelectuais, pois são eles que organizam o sentido de uma realidade dispersa) é fundamental para tanto. Um exemplo que extraio do livro. Ortiz analisa um showroom de iates em Miami, em que há um responsável por definir que iates mostrar e a quem. Para tanto ele precisa saber quem faz parte do universo do luxo 
(com acesso a tudo) e quais são os forasteiros. Seu olhar é treinado, e com poucos signos ele sabe identificar cada um. Assim ele afirma: "mais câmeras eles têm, menos riqueza possuem... é engraçado, logo que alguém me pede 'oh! tire minha foto', imediatamente eu os dispenso como pessoas não qualificadas" (Ortiz, 2019: 222).

Exemplos pitorescos como esse dão cores ao livro. Contudo, os exemplos têm uma função definida em $O$ universo do luxo; eles ilustram os argumentos que se sucedem interligados por uma proposta central: o universo do luxo é um universo particular que se baseia no princípio da diferenciação. Dessa forma, enquanto o capitalismo é flexível, o luxo é sólido; enquanto o consumo é efêmero, o luxo é estável e permanente; enquanto a produção banal é marcada pela tecnologia, a do luxo deve ser artesanal.

Essas características do luxo se sustentam porque seus praticantes habitam um mesmo espaço. Aqui reencontramos aquela agenda de pesquisa lançada em Um outro território. Na própria definição que Ortiz (20I9: 7) dá a seu objeto a noção espacial aparece: o luxo é "simultaneamente global e hiper-restrito. Dois movimentos o constituem, expansão e exiguidade". Isso significa dizer que para compreender o luxo deve-se ter em mente que ele "ocorre" em um espaço delimitado, mas que não está delimitado pela nação: um novo espaço, que se apresenta ao mesmo tempo transnacional e restrito. A noção de universo é a metáfora que Ortiz utiliza para isso (há uma inspiração na ideia de campo, de Bourdieu, mas também um afastamento). Segundo sua definição, o universo encerra duas dimensões "um núcleo central e fronteiras" (Ortiz, 20I9: 67). No núcleo estão os "produtos inacessíveis", como iates, aviões particulares, palácios, alta-costura (Ortiz, 20I9: II2), onde, idealmente, todas as práticas, os objetos, as instituições e os sujeitos se relacionam entre si em torno do luxo. A fronteira é onde essas relações se tornam mais difíceis, onde as disputas são mais frequentes e onde, em geral, estão os objetos vendidos como "de luxo" para as pessoas que não habitam aquele universo.

O universo do luxo é, portanto, simbólico. Mas também é um espaço concreto, como demonstra Ortiz. É um espaço transnacional, e o livro nos apresenta dados para mostrar como o consumo do luxo e os muito ricos se transnacionalizaram, com números muito mais crescentes na Ásia e na África do que na Europa (ver os capítulos "o mercado de bens de luxo" e o "mundo do rico"). Da mesma forma, as empresas do luxo abriram lojas em vários lugares do mundo (já qualifico essa ideia), possuindo uma atividade, de fato, global.

Importa a Ortiz notar, contudo, que ao se globalizar o universo do luxo estabelece novas fronteiras, que já não são nacionais, dentro das quais se produz sentido social e nelas só sabem navegar aqueles que pertencem a esse universo. Assim, o autor mostra que se as lojas de luxo se transnacionalizam, elas não estão em qualquer lugar. Primeiramente, con- 
centram-se em certas cidades, as mesmas que Saskia Sassen chamaria de cidades globais. Mas a noção de cidade é muito ampla, afirma Ortiz, e as lojas precisam "se situar nos bairros chiques e famosos das cidades importantes, este é o sinal inequívoco de distinção (Paris, Nova Iorque, Xangai, Londres, Moscou)" (Ortiz, 2019: 53).

Esse espaço se completa com outro, com o mundo dos ricos. Partindo de Bastide, Ortiz afirma que o mundo dos ricos é o que dá materialidade ao universo do luxo, sem o qual "seu valor simbólico permaneceria incompleto" (Ortiz, 20I9: I73). Interessante notar que também a moradia dos ricos apresenta uma cartografia, também é um espaço restrito, incrustado em certos bairros de certas cidades. Por isso mantém uma relação de convergência com o universo do luxo. Em suas palavras:

O mundo dos ricos e o universo do luxo são simultaneamente transnacionais e restritos, transcendem as fronteiras locais e nacionais para se realizarem em lugares exíguos. Isso significa que eles entretêm uma relação particular com o espaço. A transnacionalidade lhes dá a dimensão de expansão, mas a exigência de limites, a separação em relação aos outros, os aglutina em uma localidade específica (Ortiz, 2019: I89).
O autor, então, nos induz a juntar em um mapa os pontos - pontos descontínuos, mas que formam um todo - que representam as moradias dos ricos com aqueles onde estão os lugares do luxo para notarmos a produção de um novo espaço, ao mesmo tempo global e hiper-restrito. Entre esses pontos, vemos os trajetos de pessoas que se movimentam, mas não saem do lugar, e que cada vez que se movimentam mais se aprofundam na imobilidade. É por isso que Ortiz afirma que esses ricos não viajam, mas se deslocam. Para eles não há o exterior, o estranho, mas apenas o interno e o familiar. Não lhes cabe, portanto, a noção de cosmopolitas (que alguns autores querem atribuir aos ricos), pois o espaço em que o universo do luxo se encerra é uma província transnacional protegida em suas fronteiras. Nessa, seus habitantes são "globalmente provincianos” (Ortiz, 20I9: 2I3).

Recebido em 26/4/2019 | Aprovado em 9/7/2019 


\section{REFERENCIAS BIBLIOGRÁFICAS}

Durkheim, Émile \& Mauss, Marcel. (2004). Algumas formas primitivas de classificação. In: Durkheim, Émile. Durkheim. São Paulo: Ática, p. 183-203.

Ianni, Octavio. (2006). Teorias da globalização. Rio de Janeiro: Civilização Brasileira.

Ortiz, Renato. (2019). O universo do luxo. São Paulo: Editora Alameda.

Ortiz, Renato. (I999). Um outro território. São Paulo: Ed. Olho D’Água

Michel Nicolau Netto é professor do Departamento de Sociologia e coordenador geral da pós-graduação do IFCH/ Unicamp. Doutor em sociologia pela Unicamp, com estágio de doutorado na Humboldt Universität de Berlim, tem pósdoutorado em sociologia pela Unicamp. Foi visiting scholar no

ILAS/Columbia University, nos EUA, e visiting fellow, na LSE, Inglaterra. É autor de Música brasileira e identidade nacional na mundialização (2009), o discurso da diversidade e a world music (20I4) e Do Brasil e outras marcas: nação e economia simbólica nos megaeventos esportivos. Áreas de interesse: cultura, 